\title{
The Role of the Woman in the Albanian Family
}

\author{
Brikena (Buda) Dhuli \\ Aleksander Moisiu University, Durres, Albania \\ kenadhuli@yahoo.com
}

Doi:10.5901/mjss.2013.v4n10p255

\begin{abstract}
One of the main problems that contemporary societies face today is the uncertain role of the woman and the man. Women have an important role in the development of the society and culture. They also have a great impact in the development and improvement of the human race due to the close relationship and impact on the children during their upbringing. Women, the Albanian women in specific, used to be discriminated and suppressed because of various conditions of the time. After the fall of the communist regime the Albanian woman needed a lot of support, not only morally but even institutionally. There was a need for collective initiatives of feminist organizations so that women could have some of the rights which she had been unfairly prevented from. "Feminism is the struggle to protect and improve women's rights"(Giddens,A Fq14 )
\end{abstract}

\section{Abbreviations}

- $\quad$ CEDAW

- $\quad$ HDCP

- INSTAT

- QNL

- UNDP
Convention on the Elimination of All Forms of Discrimination against Women

Center to promote human development

Institute of Statistics

Centre for legislative initiatives

The development program of the United Nations

\section{Introduction}

This article aims to highlight the following issues:

- the essential role of women in the reformation and development process of the society in order to have this part of the society involved in all representative areas and levels with equal opportunities.

- the attempts of women to ensure their rights, at any time and circumstance, their struggle to ensure the respect towards their values and capacity as well as the equity in every possible decision or opportunity that can affect their future;

- the involvement of the state institutions, both public and private to enforce with seriousness and fairness all the legal acts and laws which are directly related to respecting women rights in the society;

- the uncontested role of women in the upbringing of their children, and in educating the essential moral and ethical values in the family.

\section{The historical development of women rights}

The Albanian society has undergone harsh political, economical, social and psychological developments the consequences of which have left their traces behind the fragile part of the society such as women and children. The upto-now studies on gender-based violence reinforce the Cannon (the unwritten but widely-accepted codes which have been transmitted in the Albanian society up to the 20th century) as a source of violence and mistreatment of women from their husbands, but it is not the only one. As the existence of the Canon once and forever determined the domination of men over women, the inferiority of women has been engraved as a consequence of a wide range of political, cultural, social, family, and time factors.

The post-World War II period of time marked an important turn in the attitude towards women. During this period, a "re- activation" of women was noted in order to fit to the "revolution" of the country which was later legally reflected in the Constitution of 1946. This wind of change was obviously a relief for women and girls who up to that time had been 
overruled by the exploiting and discriminating effect of the Canon, according to which beating, mistreatment, and killing of a woman were all legal. The 46-year totalitarian system, despite the massive psychological trauma created, had also an enlightening and regenerating effect in the social, economic, cultural and political role and position of women in Albania. The woman was not insignificant at home; on the contrary, she was considered an "emancipating" power for the society, equal to her husband and independent. The increasing needs for the education of women, her involvement in the educational, social and political life, brought her to a stronger position towards her husband, at least out of the house. The family code of 1982 specifically served to this position of the woman in the Albanian society of the time. In act 6 of this code, "it is sanctioned that the woman is relieved fro the economic and political suppression and has equal rights to men". However, the communist system of "apparent equity" does not have specific definitions on the existence of violence in women. It seems that system has given more freedom to women out of the house rather than inside it. Though it was never made public, mistreatment of women at home was existent and evident. The solution to this issue was added to the long list of taboos of the time. The transition period during 1990-1998, especially the economic one has highlighted gender inequity in its extreme levels. The process of moving form a centralized economic system to an openmarket system has strengthened the economical position of men, and as a consequence has also violated the independence of women. Furthermore, women have added to the unemployed lists of small units of service and home service. As a result, an increased number of unemployed women was noted which violated their social, economical and political position as well. Though it offered a wide range of freedom for women in the esthetic, and self-care aspect, the democratization of the Albanian society marked the beginning of a strong economical dependence of women on men.

The family is a moral and ideological unit which is not universally exposed but in different social orders. The family is not a natural group created by the blood need, but a range of human relations shaped by a state which recognized the family as unit in charge of ownership, enabled care and welfare, and dealt specifically with the young; a conceptualized sphere as a field of love and intimacy in opposition to much of undefined norms that dominate modern economies and policies.( Collier,J.\&Rosaldo,M.\& Yanagisako,S. Fq. 74).

Violence, threats, oppression of women in the family and their vulnerability to men's anger and physical consequences were supported (indirectly) by the legal structure that virtually bypass domestic violence. The use of violence by husbands and fathers to control the women in the family was often a sufficient force, because they were aware that they could face penalties if they failed to perform house duties or behaved differently. Divorce appears as a peripheral phenomenon and not disturbing in the Albanian society during the monist regime, by referring also to the statistics it is almost inconsiderable. The threat of divorce without the exercise of violence has often served to limit the power of women in the family especially if they were not able to support themselves, or because they were not legally able to inherit and manage their wealth. Many of the women who were in opposition to amending the equal rights did it just for the fear of divorce. Of course, women with wealth or education, or those who live in egalitarian families can not suffer in the same way with women that lack these resources. Many women rely on the love and mercy of men, or the protection of their fathers. But in most countries, historical data show that women ultimately have been subject to the power of their husbands and older men in the family to the community or state.

Anthropologists claim that the description and analysis of the position of "dependent wife", subjected to violence in the family and the state should be seen as a comparative perspective. Such scholars as Meas(1935), Friedl(1975), Leacock(1978), Hoffer(1972), and later Mac Cormarc(1974) and Rosaldo(1974) noted that the rate of women who experience domestic equity is different. Dependence is not universal and equality between spouses is based on men's aggression and greater ability to enforce their will, and as sociologists shave it "this is not an unavoidable reality of human heritage".

Women have relatively more power in contemporary Western families mainly because couples usually decide that their new-family should be independent from their families of origin. Coser (1985) suggested that in the American families, more and more women find a job which satisfies their families' material need and educational opportunities for their children. When this happens Cose noted that men lose power when women gain economic independence. This theory however showed that males often engage in social standards of the middle class where the woman earns money in the family. This is an indication, between the loss of male power at home, and the victory of a community in which the family level depends on prestige. For some families the transition from traditional to modern families, can lead to the beginning of disharmony. Tension worsens when the family ideology is based on the traditional values of the dominance of man, and finally when a significant euphoria occurs when new values of equality in culture are displayed.

Gender equality is a cornerstone in the development process of the country. To achieve it, we need to examine the causes of inequality found in the family, community, labor market and generally in the society. The division of labor by gender creates burdens (measured by time and energy), a degree of recognition (of prestige)as well as different powers 
for women and men. Gender inequality negatively affects the balance between opportunities, living conditions and social status of women and men. All over the world life is different for men and women. Usually, women have fewer rights and sources of income. These inequalities limit women's opportunities and achievements and contribute to an uneven development, and thereby perpetuate the lower status of women in society. The Albanian society is patriarchal, with different expectations regarding appropriate behavior and acceptable roles for men and women. There are many stereotypes about women, for example, women are considered inferior to men, women education is less valued, and they are just meant to be married, and so on. As a result, women have little power in terms of economic resources, have higher levels of unemployment than men, they fall victims to any kind of violence and experience small improvements to their quality of life, despite their ceaseless efforts for development. The Albanian society is patriarchal, with expectations. However, gender relations vary from one province to another and are quite visible in rural areas of Albania. Gender inequality in the Albanian society is not just a matter of human rights but also an issue of development. The integration of gender perspective is a hard work. Gender integration is concerned with the change of attitudes concerning the roles, values and status of men and women together. It has to do with changing attitudes towards the equal sharing of the responsibilities, interventions and control of resources and decision-making. Political and social change sought by gender integration is a long process but with important. The goal is to have Albanian policymakers develop policies and programs that would ensure equality between men and women in life. Among the causes that are considered as an obstacle to women's participation in politics and decision-making, is the lack of free time for women to deal with politics and to be active in participation and decision making. Of course in this situation a significant impact rests on the fact that the dominant mentality considers housework and child care as natural issues and specific obligation of women only. Indeed, this unnatural division and masculine perception of the family and household tasks and responsibility for women only, is one of the reasons that keeps her "isolated" from the political and social world. Considering the home as the most naturalized and obligatory environment only for women, in our society there is only one exaggerated concept of woman as "a lady in the family". This is often the social mentality of our society, which mostly considers politics as "inappropriate work" for women. Lack of time, excess load in family and lack of equal sharing of tasks and responsibilities within the family, have limited opportunities and the equal participation of women in political and social life. a Without the woman's release from this burden that in the Albanian society is still unfairly regarded as an exclusive task of women, who need to withstand all loads in their daily family routine, it is not possible to assume for an increase of opportunities and possibilities to be active in society. In this context, we can not talk about gender equality in society in terms of "leisure inequality" between men and women. This equality must first be placed in the family, which is one of the institutions that have indication of misbalanced gender equality. The Albanian family is the first institution that nurtures, sustains and nourishes the mentality of gender inequality between men and women, because conditions and time opportunities for "extra family" social contribution are not equal.

\section{Social and political justice}

Without the "domestic justice" there is no political and social justice, or it will as always be, a "gender utopia" which still continues to find space in the Albanian family, not only today, but historically, because of its essentially patriarchal and conservative character. In a democratic society, every individual is entitled to a much higher quality of life. This argument proves that gender integration helps not only women, but the whole family. For example, the negative effects of depression in women or limited employment opportunities for men affect all family members. Notions of justice can be used in different contexts to argue an equal participation and representation of all genders. a lot of nation and states (including Albania) have ratified various conventions and are part of a set of normative documents (for example, the Convention on the Elimination of All Forms of Discrimination against Women), and each of them sets gender equality as a fundamental principle. Despite the fact that these states are obliged to fulfill these commitments, the reality shows that the argument of justice itself, unfortunately, is often insufficient to persuade governments to mobilize adequate resources and to respect the fundamental principle that every individual has the right to be free and equal. Directorate of Equal Opportunities through the National Strategy for Development and Integration (2007-2013) and the National Strategy for Gender Equality and Against Domestic Violence and Action Plan (2007-2010) has in its objectives ,among others, even the strengthening of the legal and institutional protective mechanisms in order to ensure gender equality in Albania; Empowerment of women through her participation in decision-making, Economic empowerment of women and the increase of opportunities for employment and vocational training; Encouragement of equal access of women and girls in quality education; absence of studies and data on women's participation in decision-making within the family, and daily life observations show that the participation of women in the decision-making is associated with their level of education , 
residence, age and access to property and income The lower the education levels of women, the weaker is its decisionmaking power, because a lot fewer opportunities for employment and of providing economic independence When decision making is related to spending money, in most cases the final decision is taken by the men of the family, who also retain the right to decide on the number of children, education, migration or emigration of the family or one of the members, as well as child marriage, when it is combined Women play more informative or advisory role regarding the need to purchase a particular food or advise the sale of a family-made product. Though not very systematic, various studies show that domestic violence is widespread in the Albanian society. It does not recognize limits of age, gender, ethnicity or religious affiliation, economic status, disability, or geography, but in most reported cases women and girls are victims. Therefore, it is estimated that a third of Albanian girls and women experience some form of domestic violence. They are beaten, attacked, and in some cases abducted and trafficked for purposes of exploitation by their family members observations of the last ten years show that over a quarter of girls and women report being victims of sexual and emotional violence and that rural women are the most affected by physical violence (see Reflections, 1995; 1994.Gjermeni \& Coast, 2003 Gender Alliance for Development, 2006.) In 2004 the counseling Center for Women and girls reports that there were about 6,670 phone calls from violated women and girls According to figures of the Ministry of Internal Affairs in cases of domestic violence in 2005, according to the evidence of criminal incidents it turns out to be 102 such cases, of which 21 are murder cases, while 25 others are threatening with murder. Furthermore, children are Also victims of violence. The 2006 studies of the UNICEF show that one in five children has experienced dizziness, 1 in 14 children has tried to turn off and 1 in 4 has experienced bruising and bleeding due to attacks.

With the advent of democracy and the transition to a new system, every woman is entitled to feel free and enjoy her denied rights, up to suppression. The collapse of a system and the arrival of democracy was more promising for a new spirit that the Albanian society would take in many aspects. Democracy would open more doors and would increase the chances that all the denied rights of women were inclined towards a legal re-dimensioning as well as towards a self awareness of the society. The role of women in society and all denied rights would become an important part of social policies being addressed in their favor. In fact it seemed a very promising reality, which would eradicate social differences in society, and become a key factor for women to occupy their deserved positions.

\section{Conclusion}

These arguments indicate that from the involvement men would women in all aspects society and development, the whole country would benefit. The role and influence of women in family builds the spiritual dimension and structure of the family and the humanity in general. The contribution and the capacity of men and women in all areas can not be ignored. Rather, they need to be encouraged in order to ensure an equitable and effective development.

\section{References}

The Abanian constitution 1946;1976;1998,2008

E drejta kanunore

Family code 2004

Ligji nr.9198, date 01.07.2004, "Per barazine gjinore ne shoqeri".

Konventa për eleminimin e të gjitha formave të diskriminimit ndaj gruas.(1979 1980)

Protokolli shtese i CEDAW (1978), Ratifikuar nga Kuvendi i Shqiperise me 1993 me ligjin nr.7767, date 09.11.1993.

Anastasi,A.(2010): Te drejtat e gruas ne legjislacionin shqiptare,Tirane, ISBN: 978-92-9236-220-2.

Zaçe,V.(1999):Marredheniet martesore sipas legjislacionit shqiptar,Tirane,Dituria.

HDPC.(2002): Shqiperia dhe objektivat e zhvillimit te mijevjecarit., Tirane,Maluka Shpk.

INSTAT.(2005):Femrat dhe meshkujt në Shqipëri.Tirane

QNL.(2006):Institucionet shqiptare për mbrojtjen e gruas ne familje.Tirane

UNDP. (2011)Dhuna me baze gjinore.Tirane 